\title{
Development of an Intervention to Promote Physical Activity and Reduce Dietary Sodium Intake for Preventing Hypertension and Chronic Disease in Filipino Americans
}

\author{
Grace X. Ma, PhD ${ }^{1,2}$, Aisha Bhimla, PhD, MPH ${ }^{1}$, Lin Zhu, PhD ${ }^{1}$, Maayan Beeber, MS $^{3}$, \\ Ferdinand Aczon, MD ${ }^{4}$, Yin Tan, MD, MPH ${ }^{1}$, Sally Boyle Quinn, RN, MSN ${ }^{5}$, Omar Khan ${ }^{1}$, \\ Crystal A. Gadegbeku, MD ${ }^{5}$ \\ ${ }^{1}$ Center for Asian Health, Lewis Katz School of Medicine, Temple University, 3440 N Broad St., \\ Suite 320, Kresge East Bldg, Philadelphia, PA, 19140, USA. \\ ${ }^{2}$ Department of Clinical Sciences, Lewis Katz School of Medicine, Temple University, \\ Philadelphia, USA. \\ ${ }^{3}$ Hunter College, The City University of New York (CUNY), New York, NY, USA. \\ ${ }^{4}$ Filipino American Society of South Jersey, Inc., Mount Laurel, NJ 08084, USA. \\ ${ }^{5}$ Division of Nephrology, Temple University School of Medicine, Philadelphia, PA 19140, USA.
}

\section{Abstract}

Hypertension is a common chronic health condition affecting Filipino Americans. This pilot study examined the feasibility of addressing high rates of hypertension among Filipino Americans through the implementation of a culturally tailored education intervention. Filipino Americans living in the Greater Philadelphia Area were recruited through Community Based Organizations for participation and were engaged using a Community-Based Participatory Research (CBPR) framework. The study included pre- and post-intervention blood pressure measurements, selfreported body mass index, and questionnaires about physical activity and salt intake. The intervention to promote physical activity and reduce salt intake was conducted through two educational sessions and was accompanied by follow-up at 3 months and by the collection of urine samples for 24-hour urinary sodium intake biomarker analysis. Following intervention, a nonstatistically significant decrease in urine sodium was observed in both the intervention and the control groups. For systolic blood pressure, a reduction of $12.6 \mathrm{mmHg}$ and an increase in 5.3 $\mathrm{mmHg}$ was observed in the intervention and control groups, respectively. Diastolic pressure decreased $3.8 \mathrm{mmHg}$ for the intervention group and increased $5.6 \mathrm{mmHg}$ among controls. The

Conflict of interest

The authors declare they have no conflict of interest.

Ethical Approval

The study was approved by the Temple University Institutional Review Board. All procedures performed in studies involving human participants were in accordance with the ethical standards of the institutional and/or national research committee and with the 1964 Helsinki declaration and its later amendments or comparable ethical standards.

Informed Consent

Written consent was obtained from all participants in the study.

Animal Studies

This article does not contain any study with animals performed by any of the authors. 
culturally tailored education intervention reported here represents a promising tool for blood pressure reduction in high-risk ethnic populations. The methods used were effective for the recruitment and retention of ethnic minorities in a community-based setting.

\section{Keywords}

hypertension; culturally tailored education intervention; Community-Based Participatory Research; Filipino Americans; ethnic minorities; dietary sodium reduction

\section{INTRODUCTION}

Hypertension remains one of the most debilitating chronic conditions affecting Filipinos in the United States (U.S.) [1-8]. The prevalence of hypertension in this population is estimated to be between $51.2 \%$ and $79.0 \%$, which is significantly higher than other ethnic groups and non-Hispanic whites $[1,2,6,9,10]$. Poor diet, including increased salt consumption, and low levels of physical activity are well-established risk factors for the development of hypertension [1,6,9,11-14]. Hypertension is also associated with increased BMI [15], and overweight and obesity rates have been reported to be around 50\% among Filipinos [16-18]. In addition, Type II diabetes rates are also high among FilipinoAmericans in comparison to other Asian-American subgroups [7]. Immigration and duration of residency in the U.S. are additional factors that raise the risk of hypertension among Filipino Americans. This population represents a unique immigrant population with a rich history of residing in the U.S. Evidence indicates, however, that compared to Filipino immigrants who have been living in the U.S. for less than 14 years and to those who are U.S. born, Filipino immigrants who have had long-term U.S. residency are more likely to develop hypertension [18]. In addition, although a large majority of Filipinos are foreign-born, many Filipinos have been living in the U.S. for several years and express biculturalism, having adopted behaviors and customs of American culture [19-21].

Physical inactivity is another key modifiable risk factor that influences the development of hypertension [22]. Although anti-hypertensive responses vary, most individuals experience reductions in blood pressure following exercise [22]. Overall, the U.S. population does not obtain enough daily physical activity, and even fewer Filipinos meet physical activity recommendations [23]. In a previous assessment conducted among Filipinos in the Greater Philadelphia Area, only $24.5 \%$ of the study sample met the aerobic physical activity guidelines when compared to the national average of $49 \%$ [5]. Along with physical activity, dietary factors serve a central role in the development of hypertension. Dietary salt intake has long been associated with hypertension [24]. In the U.S., the average sodium intake was reported to be 3,526 $\mathrm{mg}$ per day [25], which is approximately $1,200 \mathrm{mg}$ above the daily recommendations in the Dietary Guidelines for Americans [26]. To our knowledge, there are no studies that have quantified the levels of salt consumption or the impact of sodium as a potential contributing factor for hypertension among Filipino Americans. However, Asian Americans experience increased salt sensitivity, which has a large impact on changes in blood pressure [27]; thus, this population may need to take extra precautions regarding sodium consumption. 
Despite the high prevalence and impact of behavioral risk factors on hypertension and chronic disease burden, efforts to prevent the occurrence of hypertension through health education and behavioral interventions among Filipino Americans have been sparse. Dietary and physical activity approaches to address chronic disease among ethnic minorities that have cultural considerations, specifically among Filipinos, are rarely implemented. A culturally tailored intervention, however, could prove crucial to addressing specific factors influencing Filipino Americans. Such interventions are associated with improved support for chronic disease management among ethnically diverse groups compared with non-tailored interventions [28,29].

The purpose of this study was to evaluate the impact of a culturally tailored program designed to encourage physical activity and reduce sodium intake on biomarkers, perceived knowledge, attitudes, and behaviors among Filipino Americans at risk of hypertension. This study utilizes novel measures to indicate dietary patterns among Filipinos through the use of urine biomarkers. The program used culturally relevant materials, health education, and community and social support to observe changes in urine sodium, in blood pressure, and in the knowledge, attitudes, and behaviors associated with salt reduction and physical activity.

\section{METHODS}

\section{Participants}

Participants were recruited through Filipino Community Based Organizations (CBO) in the Greater Philadelphia Area. Four CBOs were assigned to the intervention group, and two CBOs were assigned to the control group. Individuals were eligible to participate in the study if they self-identified as Filipino, were between 30 and 75 years of age, were not enrolled in any hypertension prevention or treatment programs and had access to a smartphone or email. Informed consent was obtained from the participants who were eligible and who had agreed to participate. A total of 71 participants were screened and deemed eligible to be in the study, and a total of 59 Filipinos completed the study to the follow-up period.

\section{Development of Study Intervention}

The Community-Based Participatory Research (CBPR) framework was used to guide the development of the study intervention. CPBR incorporates social, structural, physical, and environmental inequities by actively involving community members, organizational representatives, and researchers in all aspects of the research process [30-32]. Using CBPR principles, which included community input about issues experienced by the FilipinoAmerican study population, and meetings with community leaders, we developed an educational intervention using salt reduction and physical activity to reduce hypertension in Filipino Americans. CBO leaders assisted with the development of content for materials, provided assistance with recruitment, and participated in the coordination of workshops with the community. CBO leaders then attended training sessions to lead the educational intervention as they delivered the health education to the community. Throughout the intervention development, we sought feedback from CBO leaders regarding educational 
materials. We considered this to be a key component in the success of delivering health education to the community.

\section{Study design and procedures}

Participants belonging to CBOs were randomly assigned to either the physical activity and salt reduction group or the control group. To prevent cross-contamination of the intervention, we selected participants to a certain group based on locations remote from each other, with four sites in southern New Jersey and two in the Philadelphia area. Recruitment occurred from June 2016-December 2016. All assessments were conducted in person and were held at CBO community centers, homes, local libraries, and churches in the Greater Philadelphia

Area.

\section{Study Intervention}

The culturally-tailored intervention aimed to prevent hypertension among Filipino Americans through promoting healthy dietary and physical activity behaviors. The intervention to promote physical activity and encourage reduced salt intake included two educational sessions total that participants attended (see figure 1). Sessions were led by Filipino community health educators and covered the following topics: the Center for Disease Control and Prevention (CDC) physical activity guidelines and benefits [33], statistics on physical activity participation in the U.S. and among Filipinos, statistics on rates of high blood pressure among Filipinos, physical inactivity as a risk factor for chronic disease, types of physical activity, physical activity and blood pressure reduction, using a mobile application for physical activity tracking, addressing barriers and strategies to physical activity participation, overview of sodium in the diet, sodium as a risk factor for hypertension, sodium intake guidelines, how hypertension affects the Filipino community, and strategies for reducing salt intake. Participants also engaged in an activity that included preparing low salt meal recipes and using a mobile application to monitor salt-intake. An activity component was also included, with culturally appropriate physical activity sessions held with participants for a total of one hour and led by a certified instructor. Participants were also provided handouts highlighting the CDC physical activity guidelines, target heart rate zone, and strategies for staying active.

The control group underwent four sessions: baseline assessment, health education session 1 $\& 2$, and a 3-month follow-up during which the control group received a health education program. The total length of the intervention was two weeks. This program included overall health education, including chronic disease, cancer screening, and general check-ups, and overall lifestyle modifications that are fundamental to living a healthy life. Community health educators led these sessions. All intervention materials presented to participants were on a presentation software platform known as Prezi. This platform was used to provide a more interactive experience for participants [34].

\section{Outcome Measures}

Data were collected at baseline and at post-intervention, specifically 3-months follow-up. The baseline assessment was administered one week prior to the intervention and the followup was administered three months following the health education session 2 . The primary 
measure was the 24-hour urinary sodium intake biomarker. Secondary measures included blood pressure, changes in knowledge, attitudes, and behavior towards salt reduction; and physical activity level, and physical activity intention at baseline and 3-months. Measures are discussed in detail below.

\section{Biomarkers}

24-hour urinary biomarker: The 24-hour urine collection is the gold standard in population health studies to estimate dietary salt intake [35]. A single timed 24-hour urine collection was obtained for estimation of electrolyte excretion at baseline and 3-months follow-up. During the first sessions, study coordinators provided written and verbal instructions for participants on 24-hour urine collection, urine containers, and receptacles for collection. The first urine of the day was discarded and all urine over the following 24 hours was collected in the containers provided. Participants were instructed to keep urine containers at room temperature during collection and in a cool environment (e.g., refrigerator) at the end of collection prior to returning the sample to the $\mathrm{CBO}$ site within 48 hours of collection. In accordance with standard laboratory procedures, urinary sodium, potassium, and creatinine were measured using ion selecting electrode method by DHC 800 auto-analyzer (coefficient of variation was $1.5 \%$ for sodium and $2.5 \%$ for potassium). Creatinine was measured using the picric acid method by the DHC800 analyzer. The 24hour urine collections were assessed for completeness using creatinine excretion in relation to weight. Creatinine coefficients of 14.4 to 33.6 in men and 10.8 to 25.2 in women were classified as acceptable 24-hour urine collection $[35,36]$. Daily salt intake was estimated based on calculation of 24-hour urinary sodium excretion on the assumption that all sodium ingested was in the form of sodium chloride. A sodium-to-potassium ratio was also calculated, as an indicator of hypertension, versus observation of sodium and potassium alone.

Blood Pressure: The OMRON IntelliSense ${ }^{\circledR}$ Blood Pressure Monitor model HEM907 $\mathrm{XL}$ is a well-validated automated blood pressure device that has been widely utilized in large epidemiologic studies and clinical trials [37,38]. This device does not need initial or subsequent calibration up to 100,000 measurements [38,39]. The device measures systolic blood pressure and diastolic blood pressure levels by oscillometric methods based upon the principles of compression of the brachial artery under an elastic, inflatable cuff. Participants were seated in a chair with back supported and feet flat on the ground. Participants should not have smoked or had any caffeine within 30 minutes of taking the measurements. Blood pressure was taken in a chair with arm support or in a chair and on a table where the table provides a comfortable resting posture of the arm with mid-cuff at heart level after 5 minutes of resting. The study coordinator placed the appropriately sized cuff around the bare upper right arm so that the midpoint of the length of the bladder was over the brachial artery and the mid-height of the cuff was at heart level. Three blood pressure and pulse measurements were taken, and the average of the three readings was also recorded.

Body mass index (BMI): Height and weight were self-reported by participants. BMI was measured using height divided by weight and measured in $\mathrm{kg} / \mathrm{m}^{2}$. 


\section{Physical activity measure}

Physical activity level: Physical activity was measured using the International Physical Activity Questionnaire short form (IPAQ-short). The IPAQ-short is a 7-item selfadministered questionnaire used to measure physical activity levels in young and middle aged adults from various populations [40]. The IPAQ-short determines physical activity levels undertaken within the past 7 days [40]. For example, "During the last 7 days, on how many days did you walk for at least 10 minutes at a time? [40]." The IPAQ-short has been used in several studies around the world and is shown to be very reliable (0.66-0.88) [4143]. IPAQ responses were collected and divided by the amount of vigorous activity (average minutes per session, average hours per day, number of days per week), amount of moderate activity (average minutes per session, average hours per day, number of days per week), amount of time spent walking (average minutes per session, average hours per day, number of days per week) and sitting time. Sitting time was not included in the final physical activity calculation but expressed as a separate variable. Based on the amount of vigorous, moderate, and walking activity levels, calculations were expressed in total metabolic equivalents (MET) accumulated per week.

Physical activity intention: This measure was assessed using questions from the theory of planned behavior (TPB) and has been utilized in other physical activity studies $[44,45]$. Twenty-one questions were asked, and they belonged to five TPB constructs: attitude, subjective norm, perceived behavioral control, intention, and self-identity.

Table 1 describes the questions foreach construct and the response categories.

Physical activity knowledge: Physical activity knowledge was derived by questions based on CDC guidelines [33] for physical activity, and researchers created the questions. Four questions were asked to assess physical activity knowledge: 1) "How many minutes of moderate intensity aerobic activity do adults needs each week to stay healthy?"; 2) "How many minutes of vigorous aerobic activity is needed each week to receive health benefits?"; 3) "What is defined as moderate activity?"; and 4) "What other activity should adults do each week to receive important health benefits?"

\section{Dietary Sodium/salt behavior}

Sodium knowledge: Sodium knowledge was assessed using four questions: 1) "What is the maximum daily recommended amount of salt for a healthy adult?"; 2) "Which one of the following is the main source of salt in the average American diet?"; 3) "Do you think that eating too much salt could cause a serious health problem?"; and 4) "On a food label, what Percent Daily Value (\% DV) for sodium is considered high and should be avoided?"

Sodium reduction behavior: Five questions were used to measure sodium reduction behavior. 1) "Do you buy low-salt alternative food?"; 2) "Do you use seasoning/spices to replace cooking sauce?"; 3) "Do you add salt or soy sauce to your meals at the table?"; 4) "When eating out, do you ask the restaurant to prepare a less salty dish for you?"; and 5) "Do you avoid processed foods?" Answer choices ranged from "no" and "occasionally" to "often" and "always." 


\section{Statistical Analysis}

Descriptive statistics were reported for the socio-demographic variables and rate of hypertension. A chi-square or Fisher's exact test was used to evaluate the potential differences in dichotomous and categorical variables between the intervention and control group in the baseline socio-demographic factors. We used a repeated measures ANOVA test to determine the differences between and within subject variance among the intervention and control groups for the primary and secondary outcome measures. A generalized estimating equation was used to estimate the parameters on our model for the knowledge and behavior questions, which were expressed on a scale.

\section{RESULTS}

\section{Sample characteristics}

The sociodemographic characteristics of the intervention $(n=39)$ and control $(n=20)$ groups are presented in Table 2. Among the intervention group, the majority of participants were female (61\%), were born outside of the U.S. (91.5\%), were married (80.4\%), had been living in the U.S. for more than 10 years $(100 \%)$, had obtained a college degree or greater $(97.9 \%)$, were employed (55.3\%), had health insurance (100\%), saw a physician regularly $(97.9 \%)$, had a family history of hypertension (85.1\%), were living with hypertension (59.1\%), and monitored their blood pressure (75.6\%). Among the control group, the majority of participants were female (75.0\%), were born outside of the U.S. (100.0\%), were married (56.5\%), had been living in the U.S. for more than 10 years (100\%), had obtained a college degree or greater $(100.0 \%)$, were unemployed/student/retired (56.5\%), had health insurance (91.3\%), saw a physician regularly (95.7\%), had a family history of hypertension (87.0\%), did not have hypertension (52.4\%), and monitored their blood pressure (73.9\%). There were no statistical differences found between each group with respect to gender, country born, education level, employment status, health insurance, seeing a regular physician, having hypertension, and monitoring blood pressure. There were statistical differences in terms of marital status between the intervention and control groups.

\section{Primary outcomes}

The primary outcomes measure pre- and post-intervention are outlined in table 3 . Following the intervention, urine sodium had decreased in both the intervention and control group, but this was not statistically significant. Urine potassium had decreased in the intervention group and remained unchanged in the control group. The sodium-to-potassium ratio did not change drastically in the intervention group but decreased in the control group (not statistically significant). There were statistically significant changes in systolic blood pressure, diastolic blood pressure, and heart rate following the intervention when compared to controls. Body mass index did not change significantly between the two groups.

\section{Secondary outcomes}

The secondary outcome measures pre- and post-intervention are outlined in table 4. Attitude, subjective norm, perceived behavioral control, intention, and self-identity did not change significantly among the interventions or control groups from baseline to follow-up. 
Interestingly, physical activity levels decreased in the intervention group following the intervention, whereas physical activity levels increased in the control group. There were statistically significant differences in sodium reduction behavior and sodium knowledge experienced in the intervention and control groups, but these remained insignificant after comparing the groups.

\section{DISCUSSION}

Our study investigated the impact of a culturally relevant health education intervention and demonstrated its impact on achieving blood pressure reduction and improved knowledge about sodium reduction among study participants. Significant systolic and diastolic blood pressure reductions were observed at 3-months following the intervention, with a reduction of $12.6 \mathrm{mmHg}$ and an increase in $5.3 \mathrm{mmHg}$ in the intervention and control group respectively for systolic pressure and a reduction of $3.8 \mathrm{mmHg}$ and an increase of $5.6 \mathrm{mmHg}$ in these groups respectively for diastolic pressure. Similar to other studies, salt reduction education was associated with blood pressure reduction specifically among individuals with hypertension $[46,47]$.

Individuals in the intervention group demonstrated increased engagement in sodium reduction behaviors and increased knowledge regarding salt consumption after the intervention. These results, however, were insignificant when compared between groups. In addition, physical activity levels drastically reduced from baseline to 3-months follow-up. Future studies should incorporate more objective measures for physical activity, as relying on self-report can lead to reduced accuracy of results and over-reporting of activity levels [48]. This can have a negative impact on the ability to carry out interventions that address healthy lifestyle behaviors. Individuals may be less willing to change if they are under the assumption that they already participate in high levels of that behavior.

We observed reductions in 24-hour urine sodium following the intervention in both groups, but these results were not significant between groups. Reducing sodium intake is a nonpharmacological method for the prevention and management of blood pressure [14,49]. A large randomized clinical trial demonstrated decreases in urine sodium following a dietary intervention, which included a health education component, after 9-month, 18-month, and 30-month follow-up visits [49]. Interestingly in our study, the initial levels of urine sodium were lower than the average sodium consumed by Americans [13,25]. Many participants in our study were in the health care profession, and several may have been aware of the 24hour urine sodium test and became conscious of the amount of sodium they consumed while collecting their urine. Thus, this could have introduced bias into our study and could be a plausible reason for the lower initial urine sodium.

There is a lack of studies that address culturally relevant interventions for ethnic minorities such as Filipino Americans. Other studies for such minorities, however, have found improvements in health behaviors and chronic disease indicators [50-52]. One meta-analysis evaluating the effect of culturally tailored diabetes education programs among ethnic minorities with type II diabetes found an effect size of 0.41 in glycemic control measured by Hemoglobin (HbA1c) levels at six months following the intervention [51]. Furthermore, one 
study incorporating a mobile-based culturally tailored program to promote weight loss in Filipinos using CBPR measures showed high feasibility. The Siglang Buhay intervention, implemented in San Diego County, tested a nutrition and physical activity intervention among Filipinos and found significant changes in dietary fat consumption, fruit and vegetable intake, and physical activity levels [50]. In addition, a lifestyle intervention study conducted among Filipinos in Hawaii found significant reductions in weight and waist circumference following a culturally tailored curriculum [52].

The current study faces limitations, however. With a short intervention period, it was difficult to determine whether there would be more significant changes in urine sodium levels and blood pressure in the long-term. Future studies can be longitudinal, investigating the long-term effects of an intervention program on these indicators, Secondly, we did not track salt consumption during the intervention period, which could have provided richer data about participant behaviors. Thirdly, we did not thoroughly assess the anti-hypertensive medication adherence levels among study participants taking medication, which would have also potentially affected the study results. Finally, since the study intervention was multimodal, we lack information about which aspect of the intervention led to the greatest reduction in blood pressure. Thus, future measures can incorporate sodium tracking behaviors and physical activity behaviors more closely day to day, in order to determine which lifestyle behavior has the greatest impact on reducing blood pressure. Changes to hypertension guidelines introduced in 2018 likely will affect recommendations on the lifestyle and dietary behaviors necessary to achieve hypertension prevention and management [53]. Mentioned in a recent review of behavioral change interventions for reducing salt intake, health education may not be the only method to yield significant changes in behavior, and other types of interventions will need to be incorporated as well [54].

\section{CONCLUSION}

This feasibility study was conducted to determine whether a culturally tailored education intervention can be used in a broad community setting with a large number of participants. The methods used were effective for the recruitment of ethnic minorities and were associated with a high retention rate $(59 / 71=83 \%)$. The methodology also proved effective for conducting this study in a community-based setting with collection of biomarker data. The intervention reported here shows promising results for blood pressure reduction in a high-risk population. Future implementation of similar culturally tailored education interventions could greatly benefit the health of Filipino Americans.

\section{Acknowledgments:}

This project is supported by the U58DP005828 REACH grant (Racial and Ethnic approaches to Community Health, Principal Investigator: Grace X. Ma, PhD), funded by the Centers for Disease Control and Prevention and U54 CA221704(5) funded by the National Cancer Institute (NCI) of NIH (Contact PIs: Grace X. Ma, PhD and Olorunseun $\mathrm{O}$. Ogunwobi, $\mathrm{MD}, \mathrm{PhD}$ ). The contents of this manuscript are solely the responsibility of the authors and do not necessarily represent the official views of the NCI, NIH, Centers for Disease Control and Prevention or the Department of Health and Human Services. 


\section{REFERENCES}

1. Ursua RA, Islam NS, Aguilar DE, Wyatt LC, Tandon SD, Abesamis-Mendoza N, et al. Predictors of hypertension among Filipino immigrants in the Northeast US. J Community Health. 2013;38:84755. [PubMed: 23553685]

2. Ursua R, Aguilar D, Wyatt L, Tandon SD, Escondo K, Rey M, et al. Awareness, treatment and control of hypertension among Filipino immigrants. J Gen Intern Med. 2014;29:455-62. [PubMed: 24113806]

3. Abesamis CJ, Fruh S, Hall H, Lemley T, Zlomke KR. Cardiovascular Health of Filipinos in the United States: A Review of the Literature. J Transcult Nurs. 2016;27:518-28. [PubMed: 26243715]

4. dela Cruz FA, McBride MR, Compas LB, Calixto P-R, Van Derveer CP. White paper on the health status of Filipino Americans and recommendations for research. Nurs Outlook. 2002;50:7-15. [PubMed: 11973575]

5. Bhimla A, Yap L, Lee M, Seals B, Aczon H, Ma GX. Addressing the Health Needs of High-Risk Filipino Americans in the Greater Philadelphia Region. J Community Health. 2017;42:269-77. [PubMed: 27639868]

6. Ma GX, Lee M, Bhimla A, Tan Y, Gadegbeku CA, Yeh MC, et al. Risk Assessment and Prevention of Hypertension in Filipino Americans. J Community Health. 2017;

7. Barnes PM, Adams PF, Powell-Griner E. Health characteristics of the Asian adult population: United States, 2004-2006. Adv Data. 2008;1-22.

8. Bloom B, Black LI. Health of Non-Hispanic Asian Adults: United States, 2010-2014. NCHS Data Brief. 2016;1-8.

9. Angosta AD, Serafica R. Assessing Physical Activity Levels in Filipino Americans With Hypertension Using the Rapid Assessment of Physical Activity Questionnaire. Home Health Care Management \& Practice. 2017;29:91-5.

10. Jose P, Zhao B, Chung S, Fortmann S, Palaniappan L. PS1-46: Variation in Hypertension Prevalence Among Asian American Subgroups: Results from PACS (Pan Asian Cohort Study). Clin Med Res. 2013;11:136.

11. Kelley GA. Aerobic exercise and resting blood pressure among women: a meta-analysis. Prev Med. 1999;28:264-75. [PubMed: 10072745]

12. Cornelissen VA, Fagard RH. Effects of endurance training on blood pressure, blood pressureregulating mechanisms, and cardiovascular risk factors. Hypertension. 2005;46:667-75. [PubMed: 16157788]

13. Powles J, Fahimi S, Micha R, Khatibzadeh S, Shi P, Ezzati M, et al. Global, regional and national sodium intakes in 1990 and 2010: a systematic analysis of $24 \mathrm{~h}$ urinary sodium excretion and dietary surveys worldwide. BMJ Open [Internet]. 2013 [cited 2017 Dec 6];3. Available from: https://www.ncbi.nlm.nih.gov/pmc/articles/PMC3884590/

14. Appel LJ, Brands MW, Daniels SR, Karanja N, Elmer PJ, Sacks FM, et al. Dietary approaches to prevent and treat hypertension: a scientific statement from the American Heart Association. Hypertension. 2006;47:296-308. [PubMed: 16434724]

15. Ancheta IB, Battie CA, Tuason MT, Borja-Hart N, Ancheta CV. The prevalence of cardiovascular risk factors and diabetes increases with a body mass index of $>$ or $=23 \mathrm{~kg} / \mathrm{m} 2$ in Filipino American women. Ethn Dis. 2014;24:48-54. [PubMed: 24620448]

16. Rao G, Powell-Wiley TM, Ancheta I, Hairston K, Kirley K, Lear SA, et al. Identification of Obesity and Cardiovascular Risk in Ethnically and Racially Diverse Populations: A Scientific Statement From the American Heart Association. Circulation. 2015;132:457-72. [PubMed: 26149446]

17. Staimez LR, Weber MB, Narayan KMV, Oza-Frank R. A systematic review of overweight, obesity, and type 2 diabetes among Asian American subgroups. Curr Diabetes Rev. 2013;9:312-31. [PubMed: 23590534]

18. Bayog ML, Waters CM. Cardiometabolic risks, lifestyle health behaviors and heart disease in Filipino Americans. European Journal of Cardiovascular Nursing. 2017;16:522-9. [PubMed: 28756695] 
19. Berry B, Berry JW. Acculturation: Living successfully in two cultures. International Journal of Intercultural Relations. 2005;29:697-712.

20. Serafica R, Angosta AD. Acculturation and changes in body mass index, waist circumference, and waist-hip ratio among Filipino Americans with hypertension. Journal of the American Society of Hypertension. 2016;10:733-40. [PubMed: 27515181]

21. Vargas P, Jurado L-F. Dietary Acculturation among Filipino Americans. International Journal of Environmental Research and Public Health. 2015;13:16.

22. Hegde SM, Solomon SD. Influence of Physical Activity on Hypertension and Cardiac Structure and Function. Curr Hypertens Rep. 2015;17:77. [PubMed: 26277725]

23. Becerra MB, Herring P, Marshak HH, Banta JE. Social Determinants of Physical Activity Among Adult Asian-Americans: Results from a Population-Based Survey in California. J Immigrant Minority Health. 2015;17:1061-9.

24. Ha SK. Dietary salt intake and hypertension. Electrolyte Blood Press. 2014;12:7-18. [PubMed: 25061468]

25. Bernstein AM, Willett WC. Trends in 24-h urinary sodium excretion in the United States, 19572003: a systematic review. Am J Clin Nutr. 2010;92:1172-80. [PubMed: 20826631]

26. Department of Health US and Human Services and US Department of Agriculture. 2015 - 2020 Dietary Guidelines for Americans [Internet]. Report No.: 8th Edition. Available from: http:// health.gov/dietaryguidelines/2015/guidelines/

27. Park JB, Kario K, Wang J-G. Systolic hypertension: an increasing clinical challenge in Asia. Hypertension Research. 2015;38:227-36. [PubMed: 25503845]

28. Cooper LA, Hill MN, Powe NR. Designing and Evaluating Interventions to Eliminate Racial and Ethnic Disparities in Health Care. J Gen Intern Med. 2002;17:477-86. [PubMed: 12133164]

29. Netto G, Bhopal R, Lederle N, Khatoon J, Jackson A. How can health promotion interventions be adapted for minority ethnic communities? Five principles for guiding the development of behavioural interventions. Health Promot Int. 2010;25:248-57. [PubMed: 20299500]

30. Isreal B, Schulz AJ, Parker EA, Becker and AB. REVIEW OF COMMUNITY-BASED RESEARCH: Assessing Partnership Approaches to Improve Public Health. Annual Review of Public Health. 1998;19:173-202.

31. Israel BA, Parker EA, Rowe Z, Salvatore A, Minkler M, López J, et al. Community-Based Participatory Research: Lessons Learned from the Centers for Children's Environmental Health and Disease Prevention Research. Environ Health Perspect. 2005;113:1463-71. [PubMed: 16203263]

32. Holkup PA, Tripp-Reimer T, Salois EM, Weinert C. Community-based Participatory Research. ANS Adv Nurs Sci. 2004;27:162-75. [PubMed: 15455579]

33. CDC. Physical Activity Basics [Internet]. Physical Activity Basics. 2015 [cited 2016 Nov 11]. Available from: https://www.cdc.gov/physicalactivity/basics/index.htm

34. Duffy RM, Guerandel A, Casey P, Malone K, Kelly BD. Experiences of Using Prezi in Psychiatry Teaching. Acad Psychiatry. 2015;39:615-9. [PubMed: 25142249]

35. The INTERSALT Co-operative Research Group. INTERSALT Study an international co-operative study on the relation of blood pressure to electrolyte excretion in populations. I. Design and methods. J Hypertens. 1986;4:781-7. [PubMed: 3819392]

36. Excerpts from the WHO CARDIAC Study Protocol. Journal of Cardiovascular Pharmacology 1990. 1990;

37. Ambrosius WT, Sink KM, Foy CG, Berlowitz DR, Cheung AK, Cushman WC, et al. The design and rationale of a multicenter clinical trial comparing two strategies for control of systolic blood pressure: the Systolic Blood Pressure Intervention Trial (SPRINT). Clin Trials. 2014;11:532-46. [PubMed: 24902920]

38. Ostchega Y, Zhang G, Sorlie P, Hughes JP, Reed-Gillette DS, Nwankwo T, et al. Blood pressure randomized methodology study comparing automatic oscillometric and mercury sphygmomanometer devices: National Health and Nutrition Examination Survey, 2009-2010. Natl Health Stat Report. 2012;1-15. 
39. Ostchega Y, Nwankwo T, Sorlie PD, Wolz M, Zipf G. Assessing the validity of the Omron HEM-907XL oscillometric blood pressure measurement device in a National Survey environment. J Clin Hypertens (Greenwich). 2010;12:22-8. [PubMed: 20047626]

40. Lee PH, Macfarlane DJ, Lam T, Stewart SM. Validity of the international physical activity questionnaire short form (IPAQ-SF): A systematic review. Int J Behav Nutr Phys Act. 2011;8:115. [PubMed: 22018588]

41. Craig CL, Marshall AL, Sjöström M, Bauman AE, Booth ML, Ainsworth BE, et al. International physical activity questionnaire: 12-country reliability and validity. Med Sci Sports Exerc. 2003;35:1381-95. [PubMed: 12900694]

42. Deng HB, Macfarlane DJ, Thomas GN, Lao XQ, Jiang CQ, Cheng KK, et al. Reliability and validity of the IPAQ-Chinese: the Guangzhou Biobank Cohort study. Med Sci Sports Exerc. 2008;40:303-7. [PubMed: 18202571]

43. Dinger MK, Behrens TK, Han JL. Validity and Reliability of the International Physical Activity Questionnaire in College Students. American Journal of Health Education. 2006;37:337-43.

44. Ghazanfari Z, Niknami S, Ghofranipour F, Hajizadeh E, Montazeri A. Development and psychometric properties of a belief-based Physical Activity Questionnaire for Diabetic Patients (PAQ-DP). BMC Medical Research Methodology. 2010;10:104. [PubMed: 21062466]

45. Ahmad MH, Shahar S, Teng NIMF, Manaf ZA, Sakian NIM, Omar B. Applying theory of planned behavior to predict exercise maintenance in sarcopenic elderly [Internet]. Clinical Interventions in Aging. 2014 [cited 2017 Nov 29]. Available from: https://www.dovepress.com/applying-theory-ofplanned-behavior-to-predict-exercise-maintenance-in-peer-reviewed-article-CIA

46. Glynn LG, Murphy AW, Smith SM, Schroeder K, Fahey T. Interventions used to improve control of blood pressure in patients with hypertension. Cochrane Database of Systematic Reviews [Internet]. John Wiley \& Sons, Ltd; 2010. Available from: http://onlinelibrary.wiley.com/doi/ 10.1002/14651858.CD005182.pub4/abstract

47. Ribeiro CD, Resqueti VR, Lima Í, Dias FAL, Glynn L, Fregonezi GAF. Educational interventions for improving control of blood pressure in patients with hypertension: a systematic review protocol. BMJ Open. 2015;5:e006583.

48. Atienza AA, King AC. Comparing Self-Reported Versus Objectively Measured Physical Activity Behavior: A Preliminary Investigation of Older Filipino American Women. Research Quarterly for Exercise and Sport. 2005;76:358-62. [PubMed: 16270713]

49. Appel LJ, Espeland MA, Easter L, Wilson AC, Folmar S, Lacy CR. Effects of Reduced Sodium Intake on Hypertension Control in Older Individuals: Results From the Trial of Nonpharmacologic Interventions in the Elderly (TONE). Arch Intern Med. 2001;161:685-93. [PubMed: 11231700]

50. Dirige OV, Carlson JA, Alcaraz J, Moy KL, Rock CL, Oades R, et al. Siglang Buhay: nutrition and physical activity promotion in Filipino-Americans through community organizations. J Public Health Manag Pract. 2013;19:162-8. [PubMed: 23358295]

51. Nam S, Janson SL, Stotts NA, Chesla C, Kroon L. Effect of Culturally Tailored Diabetes Education in Ethnic Minorities With Type 2 Diabetes: A Meta-analysis. The Journal of Cardiovascular Nursing 2012;27:505-18. [PubMed: 21747287]

52. Inouye J, Matsuura C, Li D, Castro R, Leake A. Lifestyle Intervention for Filipino Americans at Risk for Diabetes. Journal of Community Health Nursing. 2014;31:225-37. [PubMed: 25356992]

53. Dominiczak AF, Kuo D. Hypertension: Update 2018. Hypertension. 2018;71:3-4. [PubMed: 29180455]

54. Trieu K, McMahon E, Santos JA, Bauman A, Jolly K-A, Bolam B, et al. Review of behaviour change interventions to reduce population salt intake. Int J Behav Nutr Phys Act [Internet]. 2017 [cited 2018 Apr 11];14. Available from: https://www.ncbi.nlm.nih.gov/pmc/articles/PMC5299724/ 


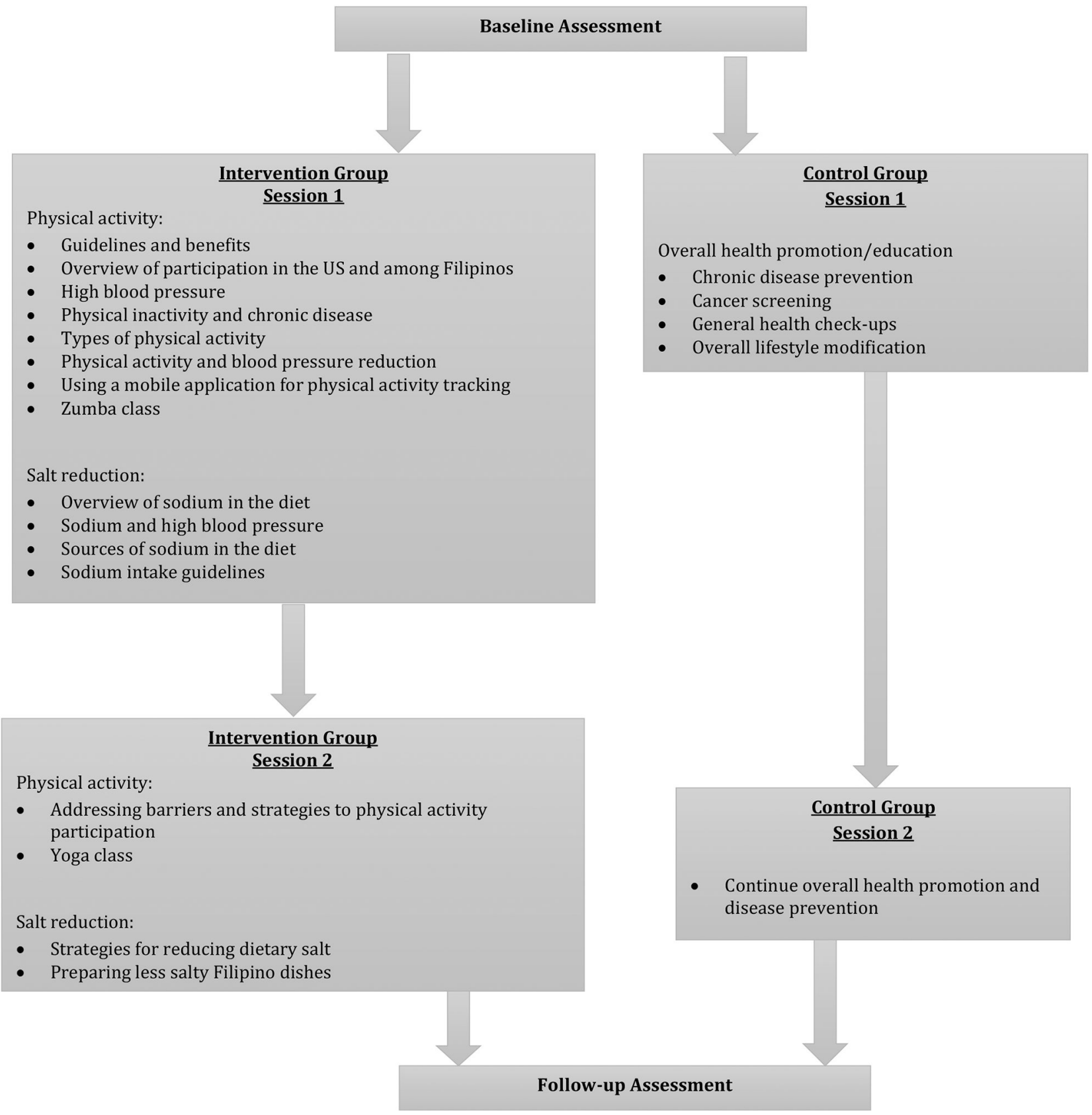

Figure 1:

Description of content for intervention and control groups 
Table 1:

Description of Theory of Planned Behavior Constructs for Physical Activity

\begin{tabular}{|c|c|c|}
\hline TPB Construct & Item & Response categories \\
\hline \multirow[t]{9}{*}{ Attitude } & $\begin{array}{l}\text { 1. Doing } 30 \text { minutes of moderate physical activity } 5 \text { days a week } \\
\text { would be... }\end{array}$ & $\begin{array}{c}\text { Very beneficial - Beneficial - Neutral - Harmful - } \\
\text { Very harmful }\end{array}$ \\
\hline & $\begin{array}{l}\text { 2. Doing } 30 \text { minutes of moderate physical activity } 5 \text { days a week } \\
\text { would be... }\end{array}$ & $\begin{array}{l}\text { Very worthwhile - Worthwhile - Neutral - } \\
\text { Worthless - Very worthless }\end{array}$ \\
\hline & $\begin{array}{l}\text { 3. Doing } 30 \text { minutes of moderate physical activity } 5 \text { days a week } \\
\text { would be... }\end{array}$ & $\begin{array}{c}\text { Very refreshing - Refreshing - Neutral - Tiring - } \\
\text { Very tiring }\end{array}$ \\
\hline & $\begin{array}{l}\text { 4. Doing } 30 \text { minutes of moderate physical activity } 5 \text { days a week } \\
\text { would be... }\end{array}$ & $\begin{array}{l}\text { Very enjoyable - Enjoyable - Neutral - Boring - } \\
\text { Very boring }\end{array}$ \\
\hline & $\begin{array}{l}\text { 5. Doing } 30 \text { minutes of moderate physical activity at least } 5 \text { days a } \\
\text { week would make me... }\end{array}$ & $\begin{array}{l}\text { Strongly satisfied - Satisfied - Neutral - } \\
\text { Unsatisfied - Strongly unsatisfied }\end{array}$ \\
\hline & $\begin{array}{l}\text { 6. For me, doing } 30 \text { minutes of moderate physical activity } 5 \text { days a } \\
\text { week would be... }\end{array}$ & $\begin{array}{c}\text { Very happy - Happy - Neutral - Unhappy - Very } \\
\text { unhappy }\end{array}$ \\
\hline & $\begin{array}{l}\text { 7. I would feel sick about not doing } 30 \text { minutes of moderate physical } \\
\text { activity at least } 5 \text { days a week. }\end{array}$ & $\begin{array}{c}\text { Strongly agree - Agree - Neutral - Disagree - } \\
\text { Strongly disagree }\end{array}$ \\
\hline & $\begin{array}{l}\text { 8. I am not motivated to do } 30 \text { minutes of moderate physical activity } \\
5 \text { days a week. }\end{array}$ & $\begin{array}{c}\text { Strongly agree - Agree - Neutral - Disagree - } \\
\text { Strongly disagree }\end{array}$ \\
\hline & $\begin{array}{l}\text { 9. I want to be healthier, doing } 30 \text { minutes of moderate physical } \\
\text { activity } 5 \text { days a week will make me healthier. }\end{array}$ & $\begin{array}{c}\text { Strongly agree - Agree - Neutral - Disagree - } \\
\text { Strongly disagree }\end{array}$ \\
\hline \multirow[t]{4}{*}{$\begin{array}{l}\text { Subjective } \\
\text { norm }\end{array}$} & $\begin{array}{l}\text { 10. My family and friends want me to do } 30 \text { minutes of moderate } \\
\text { physical activity at least } 5 \text { days a week. }\end{array}$ & $\begin{array}{c}\text { Strongly agree - Agree - Neutral - Disagree - } \\
\text { Strongly disagree }\end{array}$ \\
\hline & 11. My surroundings influence me to do physical activity. & $\begin{array}{c}\text { Strongly agree - Agree - Neutral - Disagree - } \\
\text { Strongly disagree }\end{array}$ \\
\hline & 12. I am under pressure from my family or friends to exercise. & $\begin{array}{c}\text { Strongly agree - Agree - Neutral - Disagree - } \\
\text { Strongly disagree }\end{array}$ \\
\hline & $\begin{array}{l}\text { 13. For me, it is important that I have a friend or an accompanying } \\
\text { person to exercise with me. }\end{array}$ & $\begin{array}{c}\text { Strongly agree - Agree - Neutral - Disagree - } \\
\text { Strongly disagree }\end{array}$ \\
\hline \multirow{2}{*}{$\begin{array}{l}\text { Perceived } \\
\text { behavioral } \\
\text { control }\end{array}$} & $\begin{array}{l}\text { 14. For me to do } 30 \text { minutes of moderate physical activity at least } 5 \\
\text { days a week is difficult. }\end{array}$ & $\begin{array}{c}\text { Strongly agree - Agree - Neutral - Disagree - } \\
\text { Strongly disagree }\end{array}$ \\
\hline & $\begin{array}{l}\text { 15. Doing } 30 \text { minutes of moderate physical activity at least } 5 \text { days a } \\
\text { week is up to me. }\end{array}$ & $\begin{array}{c}\text { Strongly agree - Agree - Neutral - Disagree - } \\
\text { Strongly disagree }\end{array}$ \\
\hline \multirow[t]{2}{*}{ Intention } & $\begin{array}{l}\text { 16. How likely is it possible that you would make a decision to do } 30 \\
\text { minutes of moderate physical activity at least } 5 \text { days a week in the } \\
\text { next month? }\end{array}$ & $\begin{array}{l}\text { Very likely - Likely - Neutral - Unlikely - Very } \\
\text { unlikely }\end{array}$ \\
\hline & $\begin{array}{l}\text { 17. I expect to do } 30 \text { minutes of moderate physical activity at least } 5 \\
\text { days a week. }\end{array}$ & $\begin{array}{l}\text { Very likely - Likely - Neutral - Unlikely - Very } \\
\text { unlikely }\end{array}$ \\
\hline \multirow[t]{4}{*}{ Self-identity } & 18. I see myself as sporty. & $\begin{array}{c}\text { Strongly agree - Agree - Neutral - Disagree - } \\
\text { Strongly disagree }\end{array}$ \\
\hline & 19. I see myself as fit and healthy. & $\begin{array}{c}\text { Strongly agree - Agree - Neutral - Disagree - } \\
\text { Strongly disagree }\end{array}$ \\
\hline & 20. I see myself as a physically active person. & $\begin{array}{c}\text { Strongly agree - Agree - Neutral - Disagree - } \\
\text { Strongly disagree }\end{array}$ \\
\hline & 21. Others might see me as a couch potato. & $\begin{array}{c}\text { Strongly agree - Agree - Neutral - Disagree - } \\
\text { Strongly disagree }\end{array}$ \\
\hline
\end{tabular}

J Racial Ethn Health Disparities. Author manuscript; available in PMC 2022 April 01. 
Table 2:

Baseline sociodemographic characteristics of Filipino participations in the intervention and control groups

\begin{tabular}{|c|c|c|c|}
\hline Characteristic & Intervention n (\%) & Control n (\%) & $\begin{array}{l}\chi^{2}(\mathrm{df}), \mathrm{p} \text {-value for difference by group, or Fisher exact test } \\
\text { statistics }\end{array}$ \\
\hline \multicolumn{4}{|l|}{ Gender } \\
\hline Male & $16(34.0)$ & $6(25.0)$ & 0.436 \\
\hline Female & $31(66.0)$ & $18(75.0)$ & \\
\hline \multicolumn{4}{|l|}{ Born in the United States } \\
\hline Yes & $4(8.5)$ & $0(0.0)$ & $0.195^{\ddagger}$ \\
\hline No & $43(91.5)$ & $23(100.00)$ & \\
\hline \multicolumn{4}{|l|}{ Marital status } \\
\hline Married & 37 (80.4) & $13(56.5)$ & $0.037 *$ \\
\hline Never married/single/divorced & $9(19.6)$ & $10(43.5)$ & \\
\hline \multicolumn{4}{|l|}{ Number of years in the U.S. } \\
\hline$<=10$ years & $0(0.0)$ & $0(0.0)$ & \\
\hline$>10$ years & $42(100.0)$ & $23(100.0)$ & \\
\hline \multicolumn{4}{|l|}{ Education level } \\
\hline High school education or less & $1(2.1)$ & $0(0.0)$ & $0.671^{\ddagger}$ \\
\hline College degree or greater & $46(97.9)$ & $23(100.0)$ & \\
\hline \multicolumn{4}{|l|}{ Employment Status } \\
\hline Employed & $26(55.3)$ & $10(43.5)$ & 0.352 \\
\hline Unemployed/student/retired & $21(44.7)$ & $13(56.5)$ & \\
\hline \multicolumn{4}{|l|}{ Health Insurance } \\
\hline Yes & $44(100.0)$ & $21(91.3)$ & $0.114^{\ddagger}$ \\
\hline No & $0(0.0)$ & $2(8.7)$ & \\
\hline \multicolumn{4}{|l|}{ See a regular physician } \\
\hline Yes & 46 (97.9) & $22(95.7)$ & $0.552^{\ddagger}$ \\
\hline No & $1(2.1)$ & $1(4.3)$ & \\
\hline \multicolumn{4}{|l|}{ Family history of hypertension } \\
\hline Yes & $40(85.1)$ & $20(87.0)$ & $0.535^{\ddagger}$ \\
\hline No & $2(4.3)$ & $2(8.7)$ & \\
\hline Do not know & $5(10.6)$ & $1(4.3)$ & \\
\hline \multicolumn{4}{|l|}{ Have hypertension } \\
\hline Yes & $26(59.1)$ & $10(47.6)$ & 0.384 \\
\hline No & $18(40.9)$ & $11(52.4)$ & \\
\hline \multicolumn{4}{|l|}{ Monitor your blood pressure } \\
\hline Yes & 34 (75.6) & $17(73.9)$ & 0.736 \\
\hline No & $10(22.2)$ & $6(26.1)$ & \\
\hline
\end{tabular}

J Racial Ethn Health Disparities. Author manuscript; available in PMC 2022 April 01. 


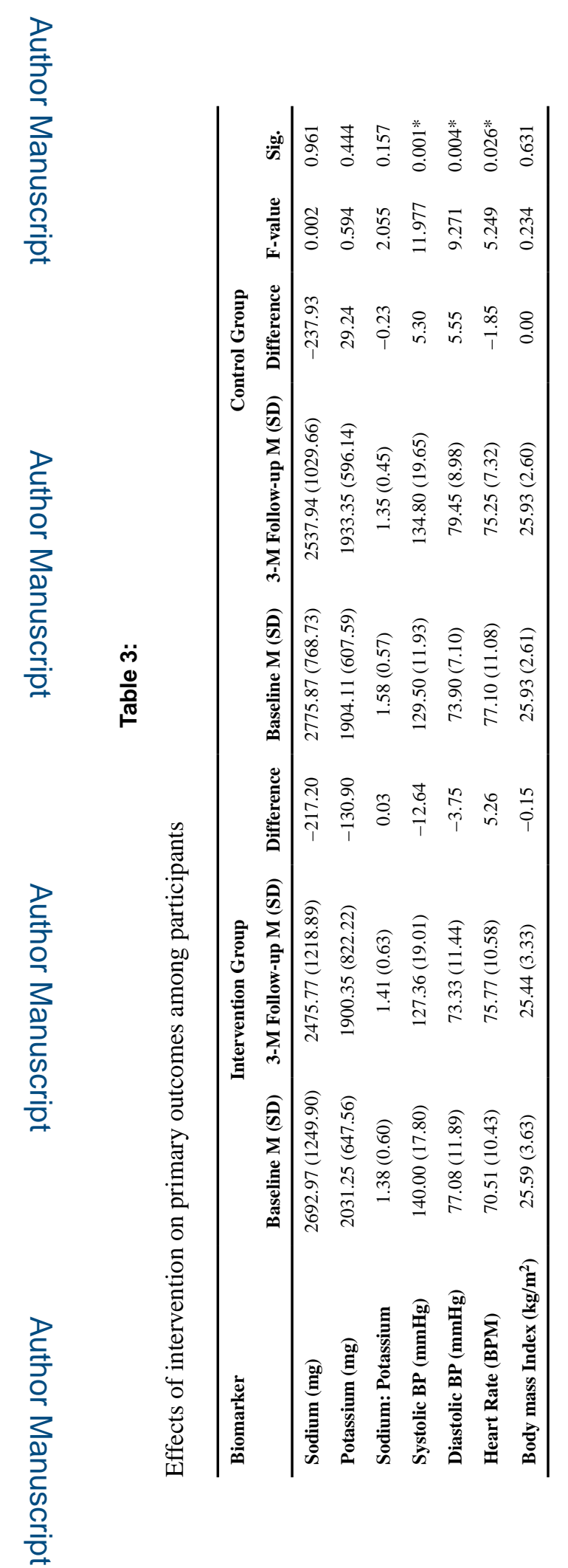

J Racial Ethn Health Disparities. Author manuscript; available in PMC 2022 April 01. 


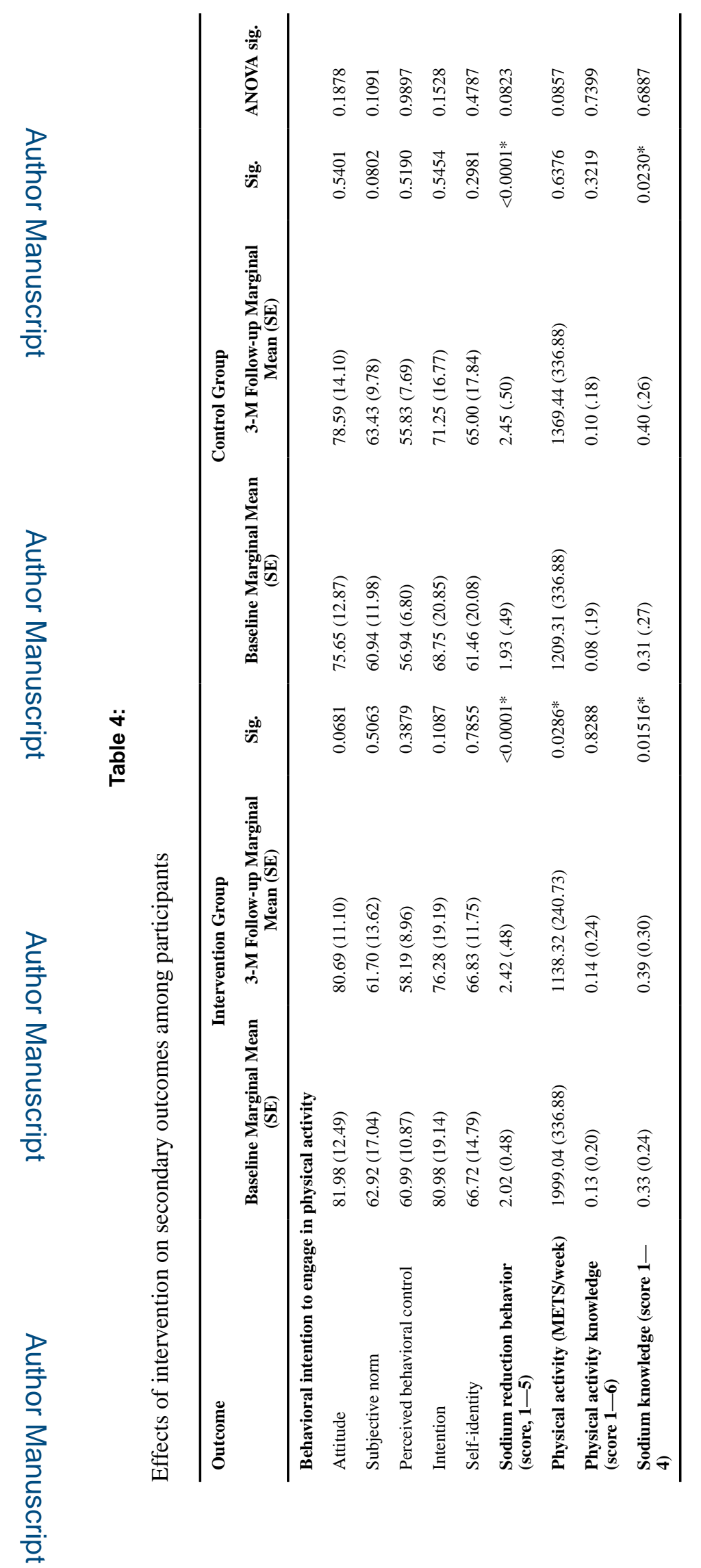

J Racial Ethn Health Disparities. Author manuscript; available in PMC 2022 April 01. 